\section{Use oil wealth to save Brazil's biodiversity}

The production of recently discovered offshore oil in Brazil

has reached 300,000 barrels a day, and is expected to rise to 2.1 million barrels a day by 2020 . Since the oil was found under a 2-kilometre layer of salt beneath the sea bed in 2006 (see Nature 455, 438-439; 2008), coastal ports have proliferated to keep pace with the boom. We suggest that some of this wealth should go into evaluating the environmental costs of such rapid development, which would help to safeguard the region's rich biodiversity.

Some ports are being constructed in conservation sites, including mangrove swamps and coastal shrub forests called restingas. Offshore oil spills are frequent (see, for example, go.nature.com/jshpzd), and pipelines are being deployed in protected areas, such as Brazil's Atlantic Forest.

President Dilma Rousseff has proposed earmarking oil royalties for investment in basic education. However, scientific research will not benefit (see Nature http://doi.org/d8zgdk; 2011) - even though it too could help to educate people in mitigating the environmental damage caused by oil production and distribution.

Renan de França Souza State University of Rio de Janeiro, Brazil. renan1604@hotmail.com

Roberto Leonan Morim Novaes, Saulo Felix Federal University of the State of Rio de Janeiro, Brazil.

\section{Tapping into success and collaboration}

Jonathan Adams' analysis cannot distinguish whether scientists collaborate internationally because they are successful, or whether they are successful because they collaborate internationally (Nature 497, 557-560; 2013).
If it is the former, then any government initiative to promote collaboration for its own sake risks simply degrading the correlation between collaboration and success, rather than improving the quality of scientific output. Impact factors and publication rates are arguably imperfect estimators of past success, and insecure guides to future success.

Michael Weale King's College London, UK. michael.weale@kcl.ac.uk

\section{Social change vital to sustainability goals}

David Griggs and colleagues argue convincingly that sustainable development goals (SDGs) should enhance the role of natural capital and ecosystem services within a framework of economic development and poverty reduction (Nature 495, 305-307; 2013). We believe that it is also crucial to factor social change into the SDG process.

It will be essential to motivate, guide and support social change towards sustainable practices at all scales of governance - globally, nationally and individually. Simply setting ambitious goals will not generate these changes: their formulation must include details of the processes needed to achieve them. For example, SDG targets should take into account ideologies, religious beliefs and institutions, including formal and informal rules and customs.

Setting targets in terms of specific and simple changes would help to overcome institutional inertia, induce desirable shifts in governance and lead to changes in people's behaviour. One such example might be to build formal accounting of carbon dioxide emissions and reporting practices into global trade and retail chains as part of international climate agreements.

Another suggestion would be to use the SDGs to create global networks for problem-solving, or social-innovation 'labs', which could catalyse new sets of rules, ways of thinking and processes for action and decision-making. Albert V. Norström ${ }^{\star}$ Stockholm Resilience Centre, Stockholm University, Sweden.

albert.norstrom@

stockholmresilience.su.se

${ }^{*}$ On behalf of 17 co-authors. See go.nature.com/i7bjjc for full list.

\section{Public engagement should start early}

Public scepticism about science, compounded by poor communication, is standing in the way of implementing sustainable technologies that could solve pressing global issues, such as the provision of sufficient clean energy, water and food (see go.nature. $\mathrm{com} / 6 \mathrm{rs} 2 \mathrm{ih}$ and go.nature. com/yvzaht). I suggest that this obstruction could be alleviated by providing more effective training for young scientists in the advantages of public engagement.

Early-career scientists may feel neither encouraged nor equipped to communicate beyond the scientific community. Current trends in performance-evaluation criteria do not seem to motivate scientists to engage more effectively with society (see go.nature.com/t43rhg).

Postgraduate education needs to include exposure to and training in social responsibility, public communication and leadership. Basic personal engagement with the United Nations Millennium Development Goals, policymakers, industries and communication specialists, for example, would lead to a more connected cohort of scientists, who could then pass their skills on to the next generation of researchers.

Bernard Slippers University of Pretoria, South Africa. bernard.slippers@fabi.up.ac.za

\section{Priming-effect author responds}

I wish to clarify your perspective on David Shanks's failure to replicate our 'intelligence priming' results (see Nature 497, $16 ; 2013$; and clarification at go.nature.com/8ep3nc).

Variations and extensions of the effect of intelligence- or stupidity-related primes on intellectual performance have been widely studied since we published our original paper (A. Dijksterhuis and A. van Knippenberg J. Pers. Soc. Psychol. 74, 865-877; 1998). These so far amount to 27 independent experiments from 12 different labs in eight countries (for instance, see A. D. Galinsky et al. J. Pers. Soc. Psychol.95, 404-419; 2008; further references available from the author). To my knowledge, Shanks et al. are the first to publish a failure to replicate our findings (although see also www.psychfiledrawer.org, which lists two single-study unsuccessful replication attempts and one successful attempt).

Given that the percentage of successful replications in psychology is low (it seems to be $30-40 \%$ ), there is no reason to assume that the intelligencepriming effect is especially difficult to reproduce. Also, since 1998 we have gained a better understanding of the mechanism underlying the priming effect (see, for example, S. L. Bengtsson et al. Soc. Cogn. Affect. Neurosci. 6, 417-425; 2011).

There are technical and methodological factors in the experimental design used by Shanks and his team that could explain their inability to replicate our results (details available from the author). For example, their general-knowledge questionnaire was unusually difficult and might have itself moderated the effect - an idea that awaits further research. Ap Dijksterhuis Radboud University Nijmegen, the Netherlands. a.dijksterhuis@psych.ru.nl 